\title{
Policymaking and Learning Actors, or Is A 'Double Movement' In Cognition Possible?
}

\section{Paolo Ramazzotti}

"The image not only makes society, society continually remakes the image." (Boulding 1956, 64)

The aim of this paper is to draw on the insights of two major scholars - Karl Polanyi and Herbert A. Simon - to discuss the nature of public policy when procedurally rational actors base their learning processes on mutually inconsistent value systems. The paper seeks to understand if there is a way out of the apparent pendulum between economic constraints to social reform and societal pressures for a humane society.

One of the key issues in Polanyi's work (1944; 1957a) is the divergence between economic and societal values in modern capitalism. This divergence, which arises as a result of the peculiarity of the market economy, eventually leads to a reaction against the rationale of the market and to what Polanyi refers to as the double movement.

Precisely because the double movement clashes with the autonomy of the market, it may disrupt it, and in so doing may lead to dramatic consequences for society, as was the case with Fascism and Nazism. It is therefore necessary to discuss whether this is the case and how it might be avoided. In this perspective, the section that follows provides a synthetic outline of Polanyi's main tenets and discusses the bounds that may preclude a movement toward a more humane economy. The distinction between internal consistency (within the market) and external consistency (between the economy and society) is introduced to adequately frame Polanyi's

\footnotetext{
The author is an Associate Professor at the Università di Macerata in Macerata, Italy. Earlier versions of this paper were presented at the ASE - Association for Social Economics Conference (Albertville, France, June 8-11, 2004), at the Storep - Italian Association for the History of Political Economy Conference (Siena, Italy, June 3-4, 2005) and at the special session on Karl Polanyi of the ESHET - European Society for the History of Economic Thought Conference (Stirling, Scotland, June 9-12, 2005). The author thanks all participants for their comments. He also wishes to thank Michele Cangiani, Maurizio Mistri, Chikako Nakayama, Stefano Perri, Claus Thomasberger and two anonymous referees for their comments on a previous version of this paper. The usual disclaimer applies.
} 
approach in the context of the subsequent theoretical debate on the meaning of embeddedness and the role of institutions in the economy.

The above bounds are apparently those outlined by neoclassical economic theory, whereby economic policy - thus action associated to the double movement may improve equity but at a cost, i.e., by reducing allocative efficiency. The key issue in this approach is that society cannot interfere with the coordinating function of the market, which is based on the information-transmitting mechanism provided by relative prices. Based on Simon's work, I argue that actors do not merely process information, they need to interpret it. Interpretation, however, need not be the same among different actors. Coordination within the market and in society requires a commonly accepted interpretative framework: a broadly intended shared knowledge must act as a meta-coordinating instance. Shared knowledge in modern capitalism, however, is strongly influenced by the interests of business. Business acts on the interpretative frameworks of other actors through propaganda but above all, through the organization of markets and production. The institutions that arise through this organizing process eventually feed back on learning processes.

The general implication of the above discussion is that if members of society are to choose what economy they want, policy must focus on how actors learn. Its action should aim not only at the material effects of economic and institutional change but also at the effects that it produces on learning. In this perspective, policy may pursue different types of shared knowledge, depending on which features of the status quo policy makers deem open to change. Insofar as it is not marginal change that they are pursuing, policy makers must view policy as a co-creator of a changeoriented knowledge.

\section{Double Movement and Bounded Change}

To adequately frame the problem, consider Polanyi's (1957a, 243) definition of the economy in its substantive sense. It is "[t]he interchange with his [man's] natural and social environment, insofar as this results in supplying him with the means of material want-satisfaction." According to Polanyi, the market economy is a specific type of economy, based on contracted exchange. Like other economic setups, it must ensure the material reproduction of society, its persistence over time. It does so through a system of price making markets. ${ }^{1}$

The economy is a part of society. The social - as opposed to merely material - reproduction of society requires that market values and societal values be consistent. Polanyi referred to the external consistency between the economy and society with his notion of embeddedness. It is in the nature of the market, however, to move toward complete autonomy, whereby it incorporates within its domain (it commodifies) features of reality that are irreducible to market values. This is the case with nature, human beings and money: unlike actual commodities, neither nature nor human beings can be manufactured according to market requirements; the same applies to money insofar as its function is the very stability and continuity of markets.

Complete autonomy of the market would lead to a social catastrophe. This 
(external) inconsistency eventually determines an opposition to the rationale of the market and causes what Polanyi termed the "double movement" whereby the movement in favor of an autonomous market is opposed by a counter-movement in favor of a self-protecting society. Block $(2000 / 2001,9)$ provides a vivid illustration of the double movement: "one might say that disembedding the market is similar to stretching a giant elastic band. Efforts to bring about greater autonomy of the market increase the level of tension. With further stretching, either the band will snap representing social disintegration - or the economy will revert to a more embedded position."

The double movement, however, conflicts with business - or sections of it and this way affects society's material and social reproduction. In some instances, it may even lead to a catastrophic outcome. Indeed, Fascism according to Polanyi arose because the double movement proved to be disruptive (Polanyi 1944, ch. 7). If we push Block's analogy to its extremes, one might suggest that re-embedding the market may also lead to a breaking point. Thus, the issue that arises is how to avoid both "snaps."

A pragmatic approach might be to rely on moderation. The problem here is what moderation consists of. For instance, is the commodification of labor acceptable provided workers are paid a fair wage? Is fairness a societal or economic value? How does a fair wage relate to a market compatible wage? Can the latter be assessed? An answer to these questions would be fairly easy if the market was conceived of as the coordinating mechanism that conventional economists have in mind. According to this view, the internal consistency of the price mechanism is a necessary condition for the material reproduction of society. Societal values (e.g., equity) may be pursued but this usually involves a loss in efficiency, measured in terms of a trade off. Thus, any action is possible but at a cost that the market itself determines. The greater the thrust toward non-market societal values, the more likely it is that the economy will be unable to ensure the material reproduction of society.

This is not Polanyi's view. He argues that the market is not the only type of economy available to society: reciprocity - a key feature of modern welfare states and redistribution - a key feature of a variety of activities ranging from household activities to charities - may either substitute or complement it. What appear to be market constraints need not constitute absolute impediments to the achievement of societal goals: alternative economic setups are possible, if the market - and the economy it is a part of - is embedded in society rather than the other way round. This does not imply, however, that alternative setups can be easily established.

To appreciate what this involves it is appropriate to focus on what embeddedness is and on the confusion surrounding two interpretations of the term. This is done in the following section. 


\section{Embeddedness and Institutions}

A range of authors has criticized Polanyi because he neglected the institutional features of the market. Hodgson (1999) acknowledges that Polanyi stressed the importance of institutions such as the state (126) and moral norms (257). Nonetheless, he endorses Barber's claim that Polanyi's notion of disembeddedness "diverts attention from the basic sociological fact that all types of exchange institutions are interdependent with their environing value patterns and other institutional subsystems" (Barber 1977, 27; quoted in Hodgson 1999, 95). Granovetter $(1985 ; 1993)$ argues that order in economic life depends on the existence of patterns of interpersonal relations that establish trust and avoid opportunism. In his view, this is what embeddedness is about. ${ }^{2}$ According to this approach, the claim that a market is disembedded involves an under-socialized view of economic activity, just as in neoclassical analysis. Block pushes the argument further by contending that Polanyi himself "provides us with some extremely important suggestions about how to carry out an analysis of the always embedded market economy, but he does not give us that systematic account" (Block 2003, 298; emphasis added).

The distinction between internal and external consistency may be of some use here. As far as the former is concerned, Polanyi provides an outlook of markets where he clearly points to the existence of "elements that can be designated as functional" (Polanyi 1957a, 267), which include custom and law. He therefore acknowledges that markets cannot be reduced to a set of relative prices. Internal consistency is not possible without institutions.

Does this mean that Barber's statement is wrong? If "diverts attention" is an understatement in that Barber actually means that Polanyi neglects institutions, then there is reason to believe that Barber misinterprets Polanyi. If, quite to the contrary, "diverts attention" were to imply that Polanyi is focusing on something else, then Barber is perfectly right. Indeed, Polanyi's primary concern is not with internal but with external consistency, i.e., with the need to "meet our present overconcern with economic matters and to achieve a level of human integration, that comprises the economy, without being absorbed by it" (Polanyi, Arensberg, and Pearson 1957, xviii). This leads him to focus on those institutional features that allow the unity and stability of the economy, which is not the same thing as the unity and stability of the market. ${ }^{3}$ In other words, when Barber states that "all types of exchange institutions are interdependent with their environing value patterns and other institutional subsystems" Polanyi would probably reply that, although this is true, it does not imply that interdependent subsystems are mutually consistent. The key issue for Polanyi is not how institutions allow the market to function but how the rationale of the market - arguably the profit motive - and the institutions that it leads to clash with a number of other institutions that underlie the societal setup. What the whole embeddedness issue is about, in Polanyi, is not the existence of institutions; it is about the existence of institutional inconsistencies. ${ }^{4}$

Some of the confusion over Polanyi may depend on Granovetter's notion of embeddedness, ${ }^{5}$ which is definitely closer to conventional views of the economy 
whereby institutions arise only as a solution to the problems that individuals face when they interact. The difficulty with his view is "not the isolation of individuals which characterises 19th century civilisation, but the functional differentiation of society, the disembedding of the economic sphere from the totality of social relationships. Modern societies, as opposed to pre-modern societies, are differentiated according to their function (and no longer by stratification). The complexity of personal relationships does not touch the question of functional differentiation of society in any way" (Thomasberger 2001, 6).

The implications for the conventional policy outlook in terms of the trade off between efficiency and equity are rather straightforward. The issue is not to assess the compatibility of redistribution or reciprocity with the allocative potential of the market but to assess the compatibility of the market with the values of society. ${ }^{6}$ The market cannot provide the criterion for an assessment because it is its functioning and its rationale that are the object of the assessment.

Simon's theoretical contribution to choice theory and cognitive theory is of major importance in understanding how this assessment is possible, thus, how society can choose the appropriate combination of redistribution, reciprocity and exchange.

\section{Choice and the Learning Process}

In a conventional (neoclassical) setting, a market is supposed to coordinate economic activity by collecting and diffusing information on the relative scarcity of resources and on individual preferences. Following this approach, undifferentiated actors are expected to choose based on the information they gather from the market. They do so by maximizing, which requires that they choose in a substantively - in Simon's (1988) sense - rational way. The problem with this approach is that the limited mental capability of human beings precludes their ability to choose in such a way, except in very special cases (Simon 1972). In general, a different approach to choice is called for. Following Simon's suggestion let us focus on the implications of procedural rationality.

Choice involves the existence of a goal, which - owing to bounded rationality - may not be clearly identified at the outset ("I want to buy a car" rather than "I want to buy model X of brand Y"). The identification of the goal is strictly related to the choice set that is available (What automobile models are available? How much can I afford to spend? How long can I keep on searching?). How these issues are dealt with - i.e., how the overall problem is framed - involves the use of existing knowledge, which provides the lens through which an actor perceives reality. Existing knowledge also provides a framework to assess whether a problem may be deemed analogous to others that were solved according to a specific procedure: analogies and heuristics are generally based on such experience. Previously acquired knowledge provides a scaffolding to support further knowledge (Newell, Shaw, and Simon 1958).

The implication is that since each individual is subject to specific experiences, learning is - at least to some extent - an idiosyncratic process. Thus, there is no absolute criterion to process the information that prices provide. Even if 
contracted exchange were to effectively transmit information throughout the economy that same data would be interpreted in different ways and the different interpretations would feed back on that very data. Contrary to the claims of conventional theory, the market cannot achieve internal consistency on the basis of information alone.

Scholars who are close to the conventional approach suggest that the solution to these problems lies in institutions. According to this view, institutions are important precisely because they constrain choice and action, thereby providing guidelines in a world of uncertainty, and in so doing they complement the market in its coordinating function (North 1990). This restrictive view of institutions, however, does not solve the issues raised by Simon's approach. Institutions - in the above meaning - need to be understood, i.e., interpreted. A signpost is not enough if it is not subject to a common - or mutually compatible - interpretation. Following Simon's contribution to economic thought, knowledge and interpretative frameworks - as opposed to information processing - are a key element if we wish to understand economic behavior and choice.

Overall knowledge includes tacit as well as explicit knowledge. Explicit knowledge is what we know that we know, and what we know that we do not know (Rooney et al. 2003). Tacit knowledge, in turn, is the background knowledge that supports explicit knowledge, thus, all those things an actor may be unaware of but without which she would be unable to understand reality. By being tacitly accepted, this knowledge avoids her effort to continuously reassess what she already (believes she) understood. Since it is taken for granted, it is one of those aspects of knowledge that is hardly questioned. ${ }^{7}$ It often includes the beliefs - i.e., explicit or implicit assumptions concerning reality - that actors resort to when they must formulate decisions but lack the required information or are unable to fit the information they have within the knowledge they have. ${ }^{8}$

Three implications are worth pointing out. First, in order for a market to coordinate economic activity, and to be internally consistent, actors must interpret that information and the interpretative frameworks they use must be mutually compatible. Since interpretative frameworks arise out of available knowledge, how the market functions ultimately depends on society's shared knowledge.

The second implication is that the distinction between external and internal consistency is not as clear-cut as one might think. External consistency - the compatibility between societal values and economic outcomes - and internal consistency - the compatibility between the economic choices of all the actors involved - both depend on the interpretative frameworks to which individuals resort. Ultimately, they depend on overall knowledge, which can hardly be split into two independent sections: the economic and the non-economic one.

The third implication is that society may avoid being disrupted by the double movement only if it shares a common view of what its goals are. In terms of both economic and societal coordination, what is required is for society's knowledge to act as a meta-coordinating instance. 


\section{Shared Knowledge as a Meta-Coordinating Device}

Given Polanyi's distinction between economy and society, it is appropriate to investigate how shared knowledge arises in the two contexts. Let us first consider business behavior, that is, the distinguishing element of a capitalist market. Business generally pursues a profit by hiring workers, producing goods and selling them to customers. Customers must know the characteristics of the goods. When they do not, they need to learn. In some instances, learning is straightforward: in most countries, people eat bread, so they search for it, try different types and eventually choose the one they prefer. There are instances, however, where people need to be informed about the very existence of a good. This typically occurs when a new product is introduced in the market. There are still other instances where information is not enough. The features of a good may be difficult to appreciate, owing to technical complexity or because the potential buyer cannot easily understand how the good is supposed to satisfy her needs. Thus, firms may sell their products only if their potential customers have both the appropriate information and the interpretative framework to appreciate that information. In most cases it is up to the firms to provide both, e.g., through advertising. They have everything to gain from doing so.

Competition among firms allows more information to be circulated. Since each firm wishes to show that its good is better than others, potential customers are in a better condition to make comparisons. Competition, however, does not always allow customers to identify appropriate interpretative frameworks. While a pharmaceutical firm will try to prove that the drug it manufactures is better than its competitor's drug, no firm will care to provide information or a cognitive framework that takes into account prevention as opposed to cure (unless there is something to gain from prevention as well). Public debate over the quality of goods occurs within an interpretative framework that is consistent with the profit constraint of the firms involved.

In fact, while drug producers may not be concerned with prevention, other firms - e.g., those that deal with environmental issues - may have an interest in dealing with it. Thus, as the range of industries potentially involved grows, the information that is circulated increases and the interpretative framework becomes more comprehensive. This would be the case where the market provides the required shared knowledge that coordination requires. In the most favorable of conditions, however, the available interpretative framework will be one where only profitable opportunities are taken into account. All interpretative frameworks that transcend the bounds set by the profit motive will be missing. While single firms may be unable to affect the market, business as a whole can organize it according to the profit motive. ${ }^{9}$

Knowledge, however, does not depend only on economic choice with its related problem-solving activities. The boundaries provided by the profit constraint are irrelevant for a great many problem solving activities. Learning may simply consist in making sense of something, independently of any direct application to choice. In fact, an individual may choose not to define boundaries too strictly or even to change them as she goes about learning. This may occur both in strictly scientific research ${ }^{10}$ as 
well as in making sense of life and choosing how to conduct it. It is also the case with Veblen's notion of idle learning.

Extra-economic interpretative frameworks may therefore arise independently of learning processes that are associated to economic choice. At the same time, however, these extra-economic interpretative frameworks may feed back on economic decisions. This is the case when ethical considerations favor market transactions - as with honesty - or when they lead to restrictions on economic activity, as with child labor or working hours. ${ }^{11}$

At this point of the argument, it should be fairly clear that markets may well be characterized by institutions of all sorts associated with both economic and extraeconomic requirements and views, but this should not deter attention from the distinctive feature of a market economy, i.e., that firms must pursue profit. The autonomy of the market (disembeddedness) does not consist in its deinstitutionalization; it consists in the subsumption of societal values and goals - such as those mentioned above on child labor - by the profit motive. This potential conflict between different perspectives suggests that contrary to Hayek $(1949,80)$, "the knowledge of the particular circumstances of time and place" that a consumer has is not all she needs to choose appropriately. She may well want to take into account more general features of knowledge. Thus, she may believe that the metric that is required to assess economic welfare need not be the same that is required to assess social well-being (Sen 1999). ${ }^{12}$

It is important to investigate what happens when different - e.g., market and non-market - interpretative frameworks clash, thereby leading to a Polanyian countermovement. Typical cases are when workers base their claim for a higher share of income on ethical principles (e.g., the human right to a decent standard of living), thus on extra-market criteria. When such claims clash with business goals, firms have to react. They have to deal with a twofold divergence. At the "real" level, they have to restore a distribution that meets the profitability requirements of the existing market. At the cognitive level, they have to restore the view (the ideology) whereby market valuation reflects the priorities of society.

Under these circumstances, the division of labor within the firm as well as among firms may be assigned a "political" task. In the first instance, the organization of production may have to be devised in such a way that the other parties do not have the bargaining power to claim higher distributive shares. A further step is to avoid even the insurgence of a distributional conflict: the parties would have to feel that the status quo is either the only or the best achievable one. These two situations are what Gramsci (1949) refers to as control and consensus, respectively. Control occurs when the parties would want to bring about an alternative but cannot. It has to do with the balance of power among the actors. Consensus implies that the actors do not think an alternative is possible. This has to do with what they know and how they acquire that knowledge. If the division of labor is devised so that workers or client firms do not know how economic activities are being carried out, this prevents actors from envisaging possible alternatives to the status quo (Marglin 1978; Ramazzotti 2004). 
These considerations may be extended to what actors deem technically possible. Technology ${ }^{13}$ is generally the outcome, through innovation, of a problem solving (i.e., learning) process, which depends on a more or less defined goal (e.g., finding a cure for malaria) and on boundaries that circumscribe the problem. Apart from available knowledge, a boundary is generally provided by the profit constraint, whereby the innovation must eventually ensure a return. From a business perspective, only potentially profitable technologies are worth seeking. It is, therefore, reasonable to believe that, owing to the prevailing distribution of world income, research in goods associated with conspicuous consumption in industrialized countries is going to be livelier and more profitable than research that tries to find appropriate drugs for tropical diseases. ${ }^{14}$ Although unexpected innovations are always possible as the unintended consequences of economic action, when technological evolution is subject to the profit constraint, it entails an overall pattern of innovation - thus technological paradigms and trajectories - that reflects privatistic rather than social priorities. Technological paradigms and trajectories that reflect business priorities eventually favor some institutional setups and mental habits while precluding others. ${ }^{15}$

The above discussion of technology - and that of the division of labor - may recall the notion of ceremonial encapsulation, i.e., the "encapsulation of technology within the ceremonial value structure of the community" (Bush and Tool 2001, 211). ${ }^{16}$ There is more to the issue, however. Once a pattern of technological change is established, it persists over time independently of the interests that led to its insurgence - i.e., it is path dependent. As Freeman points out, "[p]atterns are persistent partly because scientists, technologists, designers and others believe they will persist and act accordingly. . . . Like any institution they are sustained not by 'naturalness' but by the interests that develop in their continuance and the belief that they will continue. This belief is of course not arbitrary but is founded on previous knowledge, experimental work and discoveries" $(1994,312)$. Furthermore, that same "previous knowledge" will underlie the analogies and heuristics those researchers resort to when they pursue their research. It will feed back on the way that anybody looks at that technology: "The situation of today shapes the institutions of tomorrow through a selective, coercive process, by acting upon men's habitual view of things" (Veblen 1899, 190; quoted in Hodgson 2004, 186). ${ }^{17}$ Thus, instrumental valuation may ultimately be biased by the internalization of interpretative frameworks that are inconsistent with the material reproduction of society.

Although propaganda (ranging from advertisements to the funding of political action committees) plays an important role in the establishment of an interpretative framework, it is not its sole determinant. A major feature is the organization of markets and production, which affects what people can learn and how. The institutionalization of consumption and working patterns determines an important part of the world in which actors live. Insofar as these patterns persist over time, they tend to be taken for granted. Rather than being potentially subject to questioning, they become a part of tacit knowledge: they point to what is "socially" possible or appropriate (Zucker 1977). ${ }^{18}$ From this perspective, they provide the conditions for external consistency. A disembedded economy does not merely reflect an ideology, it also concurs in its emergence. 
To sum up, social actors learn in different ways. Their interpretative frameworks may allow them to conceive of an economy that is embedded in society rather than the other way around. This cognitive counter-movement is likely to determine a reaction in terms of a reinforcement of the interpretative frameworks that view the market economy as the only opportunity that society has. Propaganda, the division of labor and technology in general are major determinants of shared knowledge. While propaganda only acts upon the mental habits of actors, technology also provides "real" constraints to change. In terms of production processes, workers and firms cannot expect to carry out their tasks in a manner that is deemed "technically" inappropriate. In terms of output, consumers can only ask for what is available; they cannot demand what is deemed "technically" impossible to produce. These real constraints eventually feed back on mental habits, thereby preventing actors from foreseeing possible alternatives to the commodification of labor - more appropriately, the labor force - and nature. Thus, contrary to conventional views, technology provides the conditions for, rather than the constraints to, both internal and external consistency.

This double movement in cognition should not be viewed in a mechanistic fashion. Learning processes provide new outlooks on reality, so that actual outcomes may significantly differ from those envisaged by the parties involved. Furthermore, shared knowledge is only a specific, albeit distinctive, feature of culture in modern market economies. It is specific because culture includes other elements that result from the history of a specific community. It is distinctive insofar as the rationale of the market tends to underlie the organization of society. ${ }^{19}$

\section{Policymaking and Knowledge}

Let us now return to the consistency issue. Following Polanyi, I already argued that there is a wide range of possible economic arrangements, depending on how reciprocity, redistribution and contracted exchange interact. For consistency to occur both within the economy and between the economy and society, I contended that actors must share a common view of how the economy and society are (and should be) arranged, what I referred to as shared knowledge.

Shared knowledge has to do with the relation between reciprocity, redistribution and contracted exchange. It sets the priorities concerning how markets and production should be organized and those that should underlie technological evolution. It is strongly affected by institutions that relate to existing technology, the division of labor, or to consumption patterns. These, in turn, tend to reflect the interests of business.

Institutions that transcend business or even the economy as a whole may also affect shared knowledge. Values such as fairness or trust may play an important role in a wide range of economic activities but their origin often lies in religion or in other dimensions of cultural evolution. Even when they do arise out of economic interaction, actors tend to internalize them and to accept them independently of whether they are functional to their interest or not. 
The double movement reflects a breach in shared knowledge. It occurs when pressure to change the status quo clashes with vested interests, existing mental habits and/or technical constraints associated with existing technological paradigms and trajectories. Three cases are worth highlighting. First, at a strictly economic level, this breach in shared knowledge may change the business outlook (expectations): new claims on how to run the economy may increase uncertainty as to what types of conduct should and will prevail and what performance will result. In other words, the degree of turbulence of the economy may be expected to rise, all other things being equal. This may negatively affect accumulation and growth. The political effects of full employment (Kalecki 1943) provide an example. Second, at the societal level, it may undermine established views that are believed to be at the roots of existing society. Consider, for instance, how restrictions on traffic or smoking may be interpreted as detrimental to individual freedom. Third, at the technology level, it may be deemed inconsistent with the technical requirements for economic activity. Consider, for instance, resistance to anti-nuclear energy policies on the grounds that no viable alternative is available.

Since a breach in shared knowledge questions the status quo, actors cannot take the priorities underlying the economic and societal setup for granted. They must make choices. Simon's contribution to choice theory provides important insights in this regard. As I already argued, it suggests that choice may occur in different ways, depending on how actors frame their choice problems. Tacit knowledge - what actors take for granted - plays a crucial role, here. Insofar as a breach in shared knowledge forces actors to reassess precisely what they had been taking for granted, it forces them to undertake a learning process to figure out how the economy and society can and should be organized. A critical issue is how extensive the reassessment of tacit knowledge is going to be.

Actors may accept the economic, institutional and technological contexts as general bounds. Alternatively, they may act upon these general features to change them. The first approach implies that change only consists in economic and societal adaptation to external shocks and to endogenous (spontaneous) evolution. It considers the status quo as improvable only at the margin. The second approach considers the existing economic and societal setup as only one out of a range of possible ones. Between these two extremes lies a range of intermediate approaches, which are distinguished in terms of what is deemed exogenous, i.e., not subject to purposeful change.

Far from relying on a demiurgic act of will, the second approach - which we might call progressive change - assumes that change throughout all of the above contexts is possible but that it does not consist of merely deciding - possibly through elections - that a different society must be organized. It acknowledges that a major constraint occurs on cognitive grounds. Owing to the features of knowledge and learning depicted above, no valuation criterion is available that is based on an objective criterion. Rather, valuation criteria are reconstituted as society evolves. ${ }^{20}$ Societal evolution is strongly influenced by how mental habits and learning processes are affected (directly through propaganda, and indirectly through processes such as 
the division of labor and technology) by the double movement. Thus, in order to envisage an alternative to the status quo, at the individual level actors need to escape the restrictions imposed on their knowledge by the mental habits they have acquired. They must make sense of what they know in order to make sense of whatever change the economy and society (can) undergo. ${ }^{21}$

At the collective level, whatever alternative is envisaged must be compatible with existing shared knowledge. More appropriately, shared knowledge must co-evolve with economic and societal evolution. Awareness that change is possible implies a shared interpretative framework, which cannot arise other than through the interaction between economic and institutional change on the one hand, and the reconstitution of shared knowledge on the other. It involves a societal reassessment of the priorities that underlie technology, institutions, and the beliefs to which these lead.

Policymaking is necessary to ensure that internal and external consistency are achieved, but these consistencies depend on shared knowledge, thus on the image of a different societal setup - including societal goals - that is available or that gradually emerges. The scope for progressive policymaking, therefore, is to establish a specific knowledge framework, i.e., an interpretative framework of reality whereby the status quo is not taken for granted but may be progressively changed. In turn, progressive policymaking can enhance actual change only by feeding upon what social actors deem necessary as well as possible.

Progressive policymaking is, in this perspective, a special type of action because it needs to focus on the creation of new knowledge as a meta-coordinating instance. While it may involve specific technical measures, its general goal is not strictly technical; it consists of enhancing people's awareness that change is actually possible. It is this awareness that allows all individuals to carry out a search process to identify where and how it is possible to act on the economy and on society. It is the same awareness that makes them receptive to whatever change is actually occurring.

Policy makers and (sections of) the community need to interact if progressive change is to come about. However, this may not occur. Policy makers may reflect vested interests or the interpretative frameworks that defend those interests. Policy may therefore restrict the potential for a different outlook on society. Similarly, the extant shared knowledge framework may preclude people from envisaging change. There is apparently no way to predict what path society may eventually follow, but the very openness of the learning process, its irreducibility to a mere business outlook, suggests that societal change need not be bound by the latter.

\section{Final Remarks}

Polanyi's discussion of the double movement is centered on the key feature of a market economy whereby labor and nature tend to be reduced to commodities. Issues such as the decline of the welfare state, neglect of full employment policies, disregard for action that prevents environmental disruption and, more generally, the emphasis on market values and on market compatibilities as the appropriate criterion to make 
economically and socially relevant choices can be explained in terms of this rationale. The inconsistencies between the institutions of the market and those of society lead to pressures toward a different economy, where redistribution and reciprocity prevent market forces from exercising a dominant role on the economy and society. Attempts to establish such an economy, however, may have dramatic consequences: Fascism and Nazism were one such consequence.

The paper suggested that a solution to this dilemma cannot rely on the conventional notion of a trade-off, nor can it be based on some vague form of moderation. The dilemma raises a key theoretical issue, namely how to choose between different economic setups. Based on Simon's analysis of choice and cognition, the paper argued that central to the consistency of both the market and of society as a whole is the role of knowledge as a meta-coordinating instance. It also argued that, in a society where distinct interests characterize different groups of economic actors, learning occurs in different ways, that is to say, it is centered on different goals and it reflects different ways to frame a problem. Owing to the central role that knowledge plays, it is in the interest of each party to influence learning and knowledge to exert control over, or achieve the consensus of, other parties.

What is at issue is not the distortion of truth but the viewpoint chosen, thus the priorities assigned. As far as firms are concerned their priority is profit. Alternative priorities may relate to strictly economic issues such as distribution, or to issues that are generally not viewed as strictly economic - e.g., gender, the environment, world poverty, and peace - but eventually affect the way economic relations are structured in that they are associated to the relation between the market, redistribution and reciprocity.

Business acts on knowledge directly, through propaganda, but also indirectly, by organizing markets and promoting technologies that comply with its priorities and requirements. In so doing, it establishes an institutional context that actors tend to internalize and take for granted. Thus, it is true that "[d]isembeddedness is rooted in the belief that the economic system operates according to universal, natural laws" (Champlin and Knoedler 2004, 894) but this belief is not just the outcome of a social thought that eventually prevailed over others. It is the outcome of real - as opposed to mere thought - processes.

Progressive change, i.e., change that is not restricted within the bounds of a market economy and its associated business interests, involves the interaction between policy makers and (sections of) the community. Policy makers must enhance a general outlook of society whereby change of the status quo is possible. They must favor attempts to envisage different economic and societal setups. In turn, the measures they take, to change the economy and its institutions have to be consistent with the overall view of a possible society that emerges out of society itself. Thus, the solution to the double movement dilemma lies in a subtle relation between real and cognitive change.

The general conclusion of the above discussion is that formal democracy is necessary but definitely not a sufficient requirement for progressive change. A double movement in cognition is also required, which considers learning as a manifold 
process, based on the evolving institutional setup of a society. This paper only provides an outline of why this is so. I hope that further research will provide a more in-depth understanding of how this can occur. A possible step in this direction may be to extend the above inquiry to the multiplicity of collective agents that make up a community. This would overcome the implicitly assumed dualism between policymakers and society, allowing for the existence of actors - such as unions, consumer associations, and gender groups - who are also likely to contribute to the evolution of a society's shared knowledge.

\section{Notes}

1. An important characteristic of a market economy is its pervasiveness: "In so far as exchange at a rate is in question, the economy is integrated [i.e. it achieves unity and stability] by the factors that fix that rate, not by the market mechanism. Even price-making markets are integrative only if they are linked up in a system which tends to spread the effect of prices to markets other than those directly affected" (Polanyi 1957a, 255).

2. "The embeddedness argument stresses [. . .] the role of concrete personal relations and structures (or 'networks') of such relations in generating trust and discouraging malfeasance" (Granovetter 1985, 490).

3. "A study of how empirical economies are instituted should start from the way in which the economy acquires unity and stability, that is the interdependence and recurrence of its parts. This is achieved through a combination of a very few patterns which may be called forms of integration. (. . .) Empirically, we find the main patterns to be reciprocity, redistribution and exchange" (Polanyi 1957a, 250).

4. K.W. Kapp, whose views were very close to Polanyi's, provides a clear illustration of one such inconsistency between societal and market values: "If instead of 20,000 workers 20,000 heads of cattle were exposed to certain death due to an epidemic and recurrent disease, there would be an easily calculable incentive to adopt required preventive measures. The fact that the human factor of production has no capital value places it in a market economy in a less favorable position than machinery or cattle unless strong 'countervailing' and political forces interfere with the free operation of the competitive process" (Kapp 1963b, 159). Swaney and Evers (1989) highlight the similarities between Polanyi and Kapp.

5. Reference is especially to Granovetter (1985).

6. Thus, whether redistribution or reciprocity exert a positive or negative effect on market performance may be important in its own right but is not central to Polanyi's main argument.

7. What I am referring to is what M. Polanyi $(1962,267)$ denotes "the whole system of acceptances that are logically prior to any particular assertion of our own, prior to holding any particular piece of knowledge." Following this perspective, tacit knowledge is not just uncodified information.

8. Foreigners who are not informed about a country's customs and habits typically resort to their own when they interact with locals. They implicitly assume that what they deem reasonable may be so for the locals as well. More precisely, they consciously or unconsciously resort to the analogies and heuristics drawn from what they know, and apply them to situations they do not know.

9. This does not imply that the market is organized in the most profitable way. Such a claim would imply a fallacy of composition whereby what is rational from an individual point of view is also rational from a collective point of view.

10. Michael Polanyi (1962) mentions the case of research in Mathematics as one where the goals and the boundaries of the problems to be solved change as advances in the discipline occur.

11. In this perspective, the potential conflict that Sen (1982) points out, between (economic) preferences and (ethical) meta-preferences, is possible precisely because different interpretative frameworks coexist.

12. If different metrics exist, it is likely that - contrary to Coase (1988) - social costs, which are measured in terms of social well being, cannot be internalized in the price mechanism, which relates to economic welfare (Kapp 1963a; 1963b). 
13. Technology includes, for the above purposes, "tools," (individual) skills, the division of labor and related (firm and industrial) competences, independently of the way they arise and their use.

14. Cangiani $(2003,337)$ points out the relation between these considerations and Polanyi's approach: "The starting point in Polanyi's essay is that in a market economy [. . . ] the economic system tends to be self-referential. Since the choices and the very selection of information are determined or biased by 'the principle of gain and profit', 'economic' efficiency cannot be immediately and in general considered as coinciding with efficiency from the point of view of society."

15. These considerations on technology differ somewhat from Polanyi's general views. Polanyi was concerned with technology and how it affected freedom (Polanyi 1955; 1957b; 1957c). His major concern was with the strong interdependence that technology determines within society, that is to say, how it complexifies society. He pointed out that reliance on the positive effects of technological achievements may be accompanied by a high degree of uncertainty (Polanyi 1955), especially when control of technology is in the hands of a few people. He did not focus on the determinants of technology and on how they could be referred to the business requirements of market actors.

16. Bush and Tool (2001) consider, along with other possible cases, the situation where "[t]echnological innovation runs apace - giving the illusion of fundamental institutional changes - but it occurs within a system of ceremonial dominance that is preserved through sophisticated processes by which forces within the community attempt to preserve the ideology that justifies existing patterns of power and differential advantage" $(2001,214)$.

17. Hodgson (2004) refers to this process as "reconstitutive downward causation."

18. This is what Scott (1995) refers to as the cognitive pillar of institutions. See also Dequech (2002) on what he terms the "deeper cognitive function" of institutions.

19. The above discussion is consistent with Mayhew (1987) in that it reinstates the central role of culture in neoinstitutional economics. It aims to qualify this role by suggesting how a specific feature of culture tends to evolve.

20. Jennings and Waller $(1995,413)$ argue, "Despite his acknowledgement that engineers showed little inclination to coordinate and operate the industrial system along lines less devoted to the pecuniary interests they had long served, Veblen thought they could. Here lies the rub: how should the efficiency goals Veblen favored be defined, and how should they come to be so defined?" These considerations apply to engineers, policy makers and to single actors as well.

21. In neoinstitutionalist terms, "Veblen's dichotomy between invidious distinction and efficacy [. . . ] becomes an 'internal' fulcrum for cultural reinterpretation and social criticism" where 'internal' is the opposite of an "'external' fulcrum, sought in purposeless, nonhuman, mechanical cause and effect" (Jennings and Waller 1995, 413).

\section{References}

Barber, B. "The Absolutization of the Market: Some Notes on How We Got from There to Here." In Market and Morals, edited by G. Dworkin, G. Bermant, and P. Brown, 15-31. Washington D.C.: Hemisphere, 1977.

Boulding, K.E. The Image. Knowledge in Life and Society. Ann Arbor: University of Michigan Press, 1956.

Block, F. "Introduction" prepared for K. Polanyi, The Great Transformation (2001). Boston: Beacon Press, 2000 (quotations are from a mimeographed copy).

_. "Karl Polanyi and the writing of The Great Transformation." Theory and Society 32 (2003): 275-306.

Bush, P.D., and M.R. Tool. "The Evolutionary Principles of American Neoinstitutional Economics." In

Evolutionary Economics, Program and Scope edited by K. Dopfer. Boston: Kluwer, 2001.

Cangiani, M. "The Forgotten Institution." International Review of Sociology 13 (2003): 327-341.

Champlin, D.P., and T. Knoedler. "Embedded Economies, Democracy, and the Public Interest." Journal of Economic Issues 4 (2004): 893-907

Coase, R.H. The Problem of Social Cost in The Firm, the Market, and the Law, 95-156. Chicago: Chicago University Press, 1988.

Dequech D. "The Demarcation Between the 'Old' and the 'New' Institutional Economics: Recent Complications.” Journal of Economic Issues, n. 2 (2002): 565-572. 
Freeman, C. "Technical Change and Technological Regimes." In The Elgar Companion to Institutional and Evolutionary Economics, edited by G.M. Hodgson, W.J. Samuels and M.R. Tool. Aldershot: Edward Elgar Publishing, 1994.

Gramsci, A. Quaderni del Carcere, Torino: Giulio Einaudi Editore, 1949. Partial English translation: Selections from the Prison Notebooks, New York: International Publishers, 1971.

Granovetter, M. "Economic Action and Social Structure: The Problem of Embeddedness." American Journal of Sociology November (1985): 82-111

"The Nature of Economic Relationships." In Explorations in Economic Sociology, edited by R. Swedberg. New York: Russell Sage Foundation, 1993.

Hayek, F.A. "The Use of Knowledge in Society." In Individualism and Economic Order, 519-30. London: Routledge \& Kegan, London, 1949.

Hodgson, G.M. Economics and Utopia. Why the Learning Economy is not the End of History. London: Routledge, 1999.

—. The Evolution of Institutional Economics. London: Routledge, 2004.

Jennings, A., and W. Waller. "Culture: Core Concept Reaffirmed." Journal of Economic Issues XXIX, 2, June (1995): 407-18.

Kalecki, M. "Political Aspects of Full Employment." Political Quarterly, vol. XIV (1943). Also published in M. Kalecki Collected Works of Michal Kalecki. Volume 1. Capitalism: Business Cycles and Full Employment, edited by Jerzy Osiatynski; translated by Chester Adam Kisiel, 348-356. Oxford: Oxford University Press, 1990.

Kapp, K.W. "Social Costs and Social Benefits. A Contribution to Normative Economics." In Probleme der Normativen Ökonomik und der wirtschaftspolitischenBeratung. Verein fürSozialpolitik, edited by E.V. Beckerath, and H. Giersch. Berlin: Duncker \& Humblot, 1963a.

—. Social Costs of Business Enterprise. Bombay: Asia Publishing House, 1963b.

Marglin, S.A. "What Do Bosses Do? The Origins and Functions of Hierarchy in Capitalist Production." In The Division of Labor: The Labor Process and Class Struggle in Modern Capitalism, edited by A. Gorz, 13 . 54. Brighton: Harvester Press, 1978.

Mayhew, A. “Culture: Core Concept Under Attack." Journal of Economic Issues XXI, 2, (June 1987): 587 603.

Newell, A., J.C. Shaw, and H.A. Simon. "Elements of a Theory of Human Problem Solving." Psychological Review, 65, 3 (May 1958): 151-166.

North, D.C. Institutions, Institutional Change and Economic Performance. Cambridge: Cambridge University Press, 1990.

Polanyi, K. The Great Transformation. New York: Holt, Rinehart \& Winston, 1944.

__. "Our Obsolete Market Mentality: Civilization Must Find a New Thought Pattern." Commentary 3 (1947): 109-117.

—_. "Freedom and Technology." Unpublished typescript (1955), in La Libertà Complessa, , edited by A. Salsano, 170-176. Torino: Bollati Boringhieri, 1987.

—. "The Economy as Instituted Process." In Trade and Market in the Early Empires: Economies in History and Theory, edited by K. Polanyi, C.M. Arensberg, and H.W. Pearson, 243-270. New York: The Free Press, 1957a,

"The Machine and the Discovery of Society." Unpublished typescript (1957b), in La Libertà Complessa, edited by A. Salsano , 177-180. Torino: Bollati Boringhieri, 1987.

—_."Freedom in a Complex Society." Unpublished typescript (1957c), in La Libertà Complessa, edited by A. Salsano , 181-186. Torino: Bollati Boringhieri, 1987.

Polanyi, K., C.M. Arensberg, and H.W. Pearson (Eds.) "Introductory Note." In Trade and Market in the Early Empires: Economies in History and Theory, xvii-xviii. New York: The Free Press, 1957.

Polanyi, M. Personal Knowledge. Towards a Post-Critical Philosophy. London: Routledge, 1962.

Ramazzotti, P. "What Do Firms Learn? Capabilities, Distribution and the Division of Labor." In Evolution and Economic Complexity, edited by J. Foster, and S. Metcalfe. Cheltenham: Edward Elgar Publishing, 2004.

Rodriguez, J. "Endogenous Preferences and Embeddedness: A Reappraisal of Karl Polanyi." Journal of Economic Issues 1 (2004): 189-200.

Rooney, D., G. Hearn, T. Mandeville, and R. Joseph. Public Policy in Knowledge-Based Economies. Foundations 
and Frameworks. Cheltenham: Edward Elgar Publishing, 2003.

Scott, W. R. Institutions and Organizations. Thousand Oaks: Sage Publications, 1995.

Sen, A. "Rational Fools: A Critique of the Behavioural Foundations of Economic Theory." In Choice, Welfare and Measurement, 84-106. Oxford: Basil Blackwell, 1982.

Development as Freedom. New York: Alfred Knopf, 1999.

Simon, H.A. "Theories of Bounded Rationality." In Decision and Organization: a Volume in Honor of Jacob Marschak, edited by C.B. MacGuire, and C. Radner, 161-176. Amsterdam: North Holland, 1972.

_. "Rationality as Process and as Product of Thought." In Decision Making. Descriptive, Normative and Prescriptive Interactions, edited by D.E. Bell, H. Raiffa, and A. Tversky. Cambridge: Cambridge University Press, 1988.

Swaney, J.A., and M.A. Evers. "The social cost concept of K. William Kapp and Karl Polanyi." Journal of Economic Issues XXIII (1989): 7-33.

Thomasberger C. "Human Action, Economic Behaviour and Social Structure in Complex Societies. The Oversocialised Conception of Man in Modern Economics." Paper presented at the Eighth International Karl Polanyi Conference, 2001. A German version was published: "Menschliches Handeln, ökonomisches Verhalten und Sozialstrukturen in komplexen Gesellschaften. Die übersozialisierte Konzeption des Menschen in den modernen Wirtschaftswissenschaften." In Gegen den Strich, edited by Nora Fuhrmann, Eva Schmoly, and Ravinder Stephan Sing Sud, 155 165. München und Mehring: Rainer Hampp Verlag, 2003.

Zucker, L.G. "The Role of Institutionalization in Cultural Persistence." American Sociological Review 42 (1977): 726-743. 
